\title{
Pseudohomophones and word recognition
}

\author{
MICKIE VANHOY \\ University of Connecticut, Storrs, Connecticut \\ and \\ GUY C. VAN ORDEN \\ Arizona State University, Tempe, Arizona
}

\begin{abstract}
Pseudohomophones play an important role in visual word recognition research, but they are not often themselves the object of experimental inquiry. In Experiment 1, we explored whether the status of body rime relations in pseudohomophone $\mathrm{s}$ - whether their body rime relations exist in actual words-predicts the likelihood of word pronunciations to pseudohomophone spellings. In Experiment 2, we tested whether extant body rime relations modulate performance to pseudohomophones, and their context effect on word trials, in a lexical decision task. Extant body rime relations increase the likelihood that a pseudohomophone will be given a word pronunciation, and they produce slower and more error prone performance to pseudohomophones and words in lexical decision.
\end{abstract}

Pseudohomophones are nonword spellings, such as JALE, that may be pronounced like a word. Experimental studies of pseudohomophones have played a central role in discussions of phonology and reading. These studies have produced mixed results, however. For example, lexical decision responses to pseudohomophones (JALE) are often slower and more error prone than lexical decision responses to pseudoword controls (JARL; M. Coltheart, Davelaar, Jonasson, \& Besner, 1977; Meyer \& Ruddy, 1973; Rubenstein, Lewis, \& Rubenstein, 1971), but this effect is not always observed (e.g., Martin, 1982; Pugh, Rexer, \& Katz, 1994). Also, correct "yes" response times to words are usually slower in a lexical decision task that includes pseudohomophones than in one that includes pseudoword controls (Gibbs \& Van Orden, 1998; James, 1975; Stone \& Van Orden, 1993) — though Pugh et al. did not obtain this result. ${ }^{1}$ These discrepancies are important to resolve. Failures to obtain pseudohomophone effects of any sort are one basis for thinking that phonology sometimes plays no role in word recognition (McQuade, 1981; Pugh et al., 1994). Pseudohomophone effects are phonology effects. Positive phonology effects imply that phonology plays a role in word recognition; null phonology effects imply that phonology plays no role (Pugh et al., 1994; see also Jared \& Seidenberg, 1991; Taft \& van Graan, 1998).

This research was funded by a National Institutes of Health National Research Service Award (5 F32 HD08076-02) to the first author and an Independent Scientist Award to the second author (1 K02 NS 01905). The authors thank Bob Lorch, Ken Paap, Marc Brysbaert, Greg Stone, Steve Goldinger, Sue Somerville, Patrice Gibbs, Anna Bosman, Iris Berent, Jo Ziegler, and Marla Vanden Berg for helpful comments on earlier drafts of this manuscript and K. Ballein, J. Finkl, H. Ligouri, A. Powell, A. Price, and A. Smith for help with data collection. Correspondence concerning this article may be addressed to M. Vanhoy, Department of Psychology, University of Connecticut, Storrs, CT 062691020 (e-mail: mvanhoy@ altavista.com).
The experiments reported in this article may resolve the previous discrepant findings. We examined the relation between English spellings and pronunciations in an attempt to explain why some pseudohomophones produce null pseudohomophone effects. In previous experiments, researchers have sometimes used pseudohomophones with body rime relations that do not occur in English words (e.g., STAHP). Such items are hereafter called novel body rime pseudohomophones. The question in Experiment 1 was whether extant body rime relations would affect pronunciations of putative pseudohomophones. Would the existence of a pseudohomophone's body rime relation, in actual words, affect the likelihood that a pseudohomophone would be pronounced to sound like an actual word? In Experiment 2, we tested whether extant body rimes would modulate pseudohomophone effects in lexical decision performance. The pseudohomophone effects at issue in Experiment 2 were the two effects already mentioned: (1) the seminal pseudohomophone effect of Rubenstein et al. (1971), that responses to pseudohomophones (JALE) are slower and more error prone than to pseudoword controls (JARL); and (2) a context effect of pseudohomophones on word responding - that response times to words are slower in a lexical decision task that includes pseudohomophones than in one that includes pseudoword controls.

\section{EXPERIMENT 1}

Many experiments have been conducted with pseudohomophones. The large collection of their pseudohomophone items provides a natural sample with which to explore the relation between spelling and phonology. In Experiment 1, we tested putative pseudohomophones in regression analyses in order to ascertain whether body rime status constrains pronunciations. Presumably, a wellconstructed pseudohomophone reflects constraints that also affect how word spellings are pronounced. If well 
constructed, a pseudohomophone should be pronounced to sound like an actual word (e.g., JALE reliably pronounced to sound like JAIL). In Experiment 1, we tested for a correlation between the proportion of word pronunciations and extant body rime status, defined as the number of different words (type count) that include a pseudohomophone's body and rime.

Several other variables, in addition to extant body rime, were coded for each pseudohomophone, for the regression analyses. Some of these variables also pertain to body rime status, and others have been shown to affect performance to pseudohomophonesin lexical decision. We describe these variables next.

\section{Variables That Pertain to Body Rime Status}

Pronunciation consistency. SWEAT and TREAT are spelling neighbors, because they share the same spelling body (_EAT). SWEAT and TREAT are enemies, because they have inconsistent pronunciations. Their pronunciation rimes are not the same (/_et/and/_Et/, respectively); they do not rhyme. In contrast, pronunciation consistent neighbors such as DUCK and LUCK are friends; they share the same spelling body and the same pronunciation rime (Glushko, 1979). Pronunciation consistency (or feedforward consistency) is typically manipulated as a categorical variable derived by comparing the summed frequency (token count) of friends versus neighbors (Jared, 1997; Jared, McRae, \& Seidenberg, 1990). This variable reliably predicts naming performance for responses to words and pseudowords (Glushko, 1979; Seidenberg, Plaut, Petersen, McClelland, \& McRae, 1994).

Spelling consistency. Recently, the term consistency has been extended to include spelling consistency (Stone, Vanhoy, \& Van Orden, 1997). Whereas pronunciation consistency pertains to the relation from spellings to pronunciations, spelling consistency (or feedback consistency) pertains to the relation from pronunciations to spellings. Pronunciation neighborhoods may be defined on the basis of word rimes (e.g., /_Et/ is the pronunciation rime shared by /swEt/ and /trEt/) and pronunciation rimes may have more than one spelling. In the previous example, /swEt/ and /trEt/ are enemies; they share the same rime, but their bodies have different spellings (_EET in SWEET vs. _EAT in TREAT). By comparison, DUCK and LUCK are friends because they share the same rime and the same body. Both pronunciation and spelling consistency affect performance in laboratory reading tasks (in addition to previous citations, see, e.g., Frost, Fowler, \& Rueckl, 1998; Ziegler, Montant, \& Jacobs, 1997; Ziegler \& Van Orden, 2000).

\section{Additional Coded Variables}

Orthographic similarity. Orthographic similarity (OS) is an index of spelling similarity, calculated between pseudohomophones and their base words (the formula is published in Van Orden, 1987). OS reliably predicts performance in response to pseudohomophonesin lexical decision, categorization, and proofreading tasks. Pseudohomophones that are spelled similarly to base words are more likely to be mistaken for their base words, leading to false positive errors (Bosman \& de Groot, 1996; Van Orden, Johnston, \& Hale, 1988; Van Orden et al., 1992). OS is typically a control variable in manipulations of pseudohomophone phonology, whereby two letter strings can be approximately equal in spelling similarity to a third letter string. This is the reason for the term orthographic similarity. With respect to the present concerns, however, the term is a misnomer. Similarity in spelling is highly correlated with similarity in phonology. Letter strings that share the same letters also share the same potential grapheme-phoneme relations. Consequently, OS also estimates similarity in statistical relations between spellings and pronunciations. In particular, it estimates similarity in grapheme-phoneme relations that is not accounted for in body rime statistics.

Coltheart $N$. This variable was included because Martin (1982) claimed that Coltheart $N$ is the source of pseudohomophone effects in lexical decision (cf. Laxon, Masterson, Pool, \& Keating, 1992). But reliable pseudohomophone effects have been found when Coltheart $N$ (Besner \& Davelaar, 1983; McCann, Besner, \& Davelaar, 1988) and other orthographic scores (Fera \& Besner, 1992) are included as control variables. Coltheart $N$ is the number of words that can be formed by a change in one letter position; this number also estimates how often the unchanged letters co-occur across words. To the extent that these letters also co-occur with phonology, Coltheart $N$ may estimate spelling-phonology correspondence. Thus, there is a natural confound in English for benefits correlated with Coltheart $N$ and benefits correlated with the statistical regularity between spelling and phonology. This agrees with the general finding in English that statistically regular words and high Coltheart $N$ words are named more quickly.

Owing to the previous confound, Andrews (1997) proposed that Coltheart $N$ may be a spurious predictor variable, and Ziegler and Perry (1998) corroborated this hypothesis for performance on words in an English lexical decision task. If Coltheart $N$ is a spurious predictor, that may explain why it is occasionally correlated with interference effects (and not consistently correlated with better performance). For example, within Coltheart $N$ neighborhoods, Perea (1998) found that higher frequency word neighbors that differed from a target word by an interior letter generated greater interference effects than did neighbors that differed in other letters, in a priming paradigm. Especially critical were letters in the third or fourth position, close to vowel positions. Neighbors defined around these positions are more likely than neighbors in other positions to influence vowel pronunciations, which may exacerbate, via priming, the effects of local inconsistencies in relations between spelling and phonology. Local patterns of inconsistency affect word naming and implicate statistical regularity between spelling and phonology (Patterson \& Behrmann, 1997).

Base-word frequency predicts performance to pseudohomophones in lexical decision, categorization, and proof- 
reading tasks. Pseudohomophones that sound like relatively low-frequency base words are more likely to be mistaken for their base words (Van Orden et al., 1988; Van Orden et al., 1992).

Number of letters is not associated with a theoretical hypothesis. It estimates constraints that are confounded with stimulus length (Spieler \& Balota, 1997). For example, longer letter strings tend to have fewer neighbors (Andrews, 1997).

\section{Method}

Participants. One hundred twenty undergraduates enrolled at Arizona State University served as participants in partial fulfillment of a course requirement. All were native speakers of English with normal or corrected vision. Each student was randomly assigned to one of six list conditions and was tested individually. No student participated in more than one list condition (or experiment).

Stimuli. The key items were 550 putative pseudohomophones, from a total of 660 published pseudohomophone items from 10 stimulus lists (see V. Coltheart, Avons, Masterson, \& Laxon, 1991; Laxon et al., 1992; Lukatela \& Turvey, 1991, 1994; McCann \& Besner, 1987; McRae, Jared, \& Seidenberg, 1990; Pugh et al., 1994; Stone \& Van Orden, 1992, 1993; Van Orden et al., 1992). All 660 items were presented, and 550 met the criteria for analysis. Stimuli that were regionally dependent (e.g., FAWK for FORK) were excluded, as well as polysyllabic items, leaving 550 putative pseudohomophones. The 660 presented items were divided into 6 lists of 110 each. To each list we added 440 pronounceable pseudoword (JARL) filler trials, creating a 4:1 ratio between filler pseudowords and pseudohomophones and a total of 550 trials in each of the participant conditions. Ten additional pseudowords served as practice stimuli.

Procedure. Pseudohomophone pronunciations were collected in a speeded naming task. To keep pace with the speeded naming task, the experimenter transcribed only nonhomophonic pronunciations, but all pronunciations were recorded for a later, second transcription (interrater reliability $=.94$ ). Each trial's stimulus and response were evident to the experimenter, but the second transcriber heard only the audio recording and did not know the order of stimulus presentation in a recorded session. Items appeared on IBM XT clones in sound-attenuated booths. Participants sat (about) $50 \mathrm{~cm}$ from monitors, so that a letter subtended a visual angle of $22^{\prime}$ horizontal and $50^{\prime}$ vertical. Each trial began with a fixation point $(+)$ presented at the center of the screen (and the forthcoming letter string). The "+" disappeared after $500 \mathrm{msec}$, whereupon it was immediately replaced by a nonword to be read aloud. After each response, the pronunciations were noted by the experimenter, who sat within view of the monitor, behind and to the right of the participant. The participant's press on the space bar began the next trial. The 10 initial practice trials were followed by 550 test trials. Stimulus order was randomized for each participant.

\section{Results and Discussion}

The dependent variable was the proportion of homophonic pronunciations for each pseudohomophone candidate (380 of the 550 putative pseudohomophones, $69 \%$, elicited homophonic pronunciations from all the participants). The overarching goal in Experiment 1 was to map out the correlations among item variables and the proportion of homophonic pronunciations that each pseudohomophone produced. The guiding assumption was that body rime status constrains pseudohomophone pronunciations. Analyses tested whether predictors remain reliable after shared variance with other predictors is partialed out. The alpha level for all statistical tests in this article was $p<.05$. The coded variables were the following:

Extant body rime, coded as the number of English words (type count) that share a pseudohomophone's body and rime, or "0" for novel body rimes.

Pronunciation consistency, coded as 1 if the summed frequency (token count) of word pronunciation friends, for the pseudohomophone's spelling body, was larger than the summed frequency of enemies, or -1 if vice versa.

Spelling consistency, coded as 1 if the summed frequency of word spelling friends, for the pseudohomophone's pronunciation rime, was larger than the summed frequency of enemies, or -1 if vice versa.

The interaction of pronunciation and spelling consistency was coded as the product of the two previous codes. (Stone et al., 1997, observed a reliable interaction between pronunciation and spelling consistency in lexical decision performance to words.)

Orthographic similarity (OS) is an index that varies from 0 to 1 , where 1 indicates identical spelling.

Coltheart $N$ estimates the total number of English words that can be formed from a target letter string by keeping all its letters the same, except one.

Base word frequency from Kučera and Francis (1967). The number of letters in each pseudohomophone.

Estimates of body rime statistics and Coltheart $N$ were derived from a comparison with all single-syllable words in Kučera and Francis (1967; compare with Stone et al., 1997). Base word frequency, number of letters, and Coltheart $N$ were not reliably correlated with performance on the pseudohomophones(all $\left.F_{\mathrm{S}}<1\right)$ and were dropped from the analyses. As for Coltheart $N$, its failure to predict pseudohomophone pronunciations adds weight to Andrews's (1997) hypothesis that it is a spurious predictor.

A regression model that included the remaining variables accounted for approximately $12 \%$ of the variance $\left[F(5,544)=15.01, M S_{\mathrm{e}}=6.5\right]$. Pronunciation consistency and extant body rime reliably accounted for unique variance $\left[5.2 \%, F(1,544)=19.38, M S_{\mathrm{e}}=6.7\right.$, and $1.3 \%$, $F(1,544)=8.06, M S_{\mathrm{e}}=6.6$, respectively], and the unique variance associated with orthographic similarity approached statistical reliability $[0.6 \%, F(1,544)=3.64$, $\left.M S_{\mathrm{e}}=6.5, p<.06\right]$. Neither spelling consistency nor the interaction of pronunciation and spelling consistency was reliably correlated with unique variance $[0.3 \%, F(1,544)=$ $1.67, M S_{\mathrm{e}}=6.5, p>.19$; and $0.0 \%, F(1,544)=0.05$, $M S_{\mathrm{e}}=6.5, p>.80$, respectively].

The only variables that survived the regression analysis were extant body rime and pronunciation consistency, which are associated with body rime status and statistical regularity between spelling and phonology. The variable spelling consistency, which also concerns body rime status, conspicuously failed the regression test. In hindsight, spelling consistency was an unlikely variable for predicting performance on pseudohomophones. Almost all the pseudohomophones are spelling inconsistent in their rime body relation. Only pseudohomophones constructed from spelling changes outside the body rime re- 
lation have potentially consistent rime body relations (e.g., KURSE for CURSE, which, strictly speaking, is spelling inconsistent in the onset-head $[/ \mathrm{k} /-\mathrm{K}]$ relation; cf. Lukatela \& Turvey, 2000).

\section{EXPERIMENT 2}

Experiment 1 established that body rime status constrains pronunciation responses to putative pseudohomophones. Nevertheless, some items with novel body rimes reliably produced word pronunciations. Perhaps these items' success reflected finer grained constraints, such as predictive grapheme-phoneme relations (or other reliable correlations between spelling and phonology). Extant body rime relations supply constraints in conjunction with grapheme-phoneme constraints (not instead of grapheme-phoneme constraints; see Van Orden, Pennington, \& Stone, 1990). A reasonable hypothesis is that grapheme-phoneme relations, body rime relations, wholeword-size relations, and other statistical relations simultaneously constrain word naming (cf. Kawamoto \& Zemblidge, 1992; Patterson \& Behrmann, 1997; Plaut, 1997; Seidenberg et al., 1994; Stone et al., 1997; Stone \& Van Orden, 1994; Van Orden \& Goldinger, 1994).

The previous constraints may also determine lexical decision performance on word and nonword items. Hypothetically, it matters for lexical decisions whether a pseudohomophone letter string may enter a coherent resonance with word phonology. In a model, coherent resonance refers to a stable attractor pattern of interactive activation - stable feedback - among spelling and phonology nodes and among phonology and semantic nodes (cf. Farrar \& Van Orden, 2000). Coherence refers to the degree of order that emerges, over time, in interactive activation. We assume that the degree of order in interactive activation discriminates words from nonwords. A general version of this hypothesis was proposed by Lewenstein and Nowak (1989a, 1989b) to explain the discrimination of familiar from unfamiliar stimuli (cf. Skarda \& Freeman, 1987; Vallacher \& Nowak, 1997). In Experiment 2, we tested a specific coherence hypothesis derived from the umbrella hypothesis. If the degree of order in interactive activation is the basis for judging an item as a familiar English word, then it is not activation of word phonology by itself that is the basis of pseudohomophone effects. Pseudohomophones become word-like when they may achieve a relatively coherent resonance with word phonology and extant body rime relations allow a more coherent resonance. The advantage of this working hypothesis is that everything was in place, before the fact, to predict an effect of body rime status (Gibbs \& Van Orden, 1998; Stone et al., 1997; Vanhoy, 1997; Van Orden \& Goldinger, 1994). Nevertheless, other accounts of lexical decision performance could surely accommodate a body rime effect.

Experiment 2 included two tests of the previous hypothesis. One concerned the classic pseudohomophone effect: Lexical decision in response to pseudohomophones is slower and more error prone than to control foils ( $\mathrm{Ru}-$ benstein et al., 1971), but we expanded the usual experimental design to manipulate extant body rime (e.g., JALE) versus novel body rime (e.g., JAEL). Extant and novel pseudohomophones were yoked to each other and to control foils (e.g., JARL). We may expect, at least, that extant pseudohomophones (JALE) should be more difficult to discriminate from words than would control foils (JARL). The stronger test of our hypothesis is the contrast between extant and novel pseudohomophones, however. Extant body rime pseudohomophones (JALE) should produce a more coherent resonance with phonology and should be more difficult to discriminate from words than should pseudohomophones with novel body rime relations (JAEL). The more difficult discrimination should be reflected in slower "no" responses or higher error rates to extant body rime pseudohomophones.

Another test concerned the context effect of pseudohomophones: Responses are slower and more error prone to words in a context of pseudohomophones (JALE) than to the same words in a context of control pseudowords (JARL; e.g., Gibbs \& Van Orden, 1998; James, 1975; Stone \& Van Orden, 1993). This context effect is not always reliable, however (e.g., Pugh et al., 1994). ${ }^{2}$ We seek to explain the interaction of pseudohomophone context and word performance in a way that may also explain the occasional reduction or absence of this context effect. We may expect that extant body rime pseudohomophones (JALE) achieve a more coherent word-like resonance than novel body rime pseudohomophones (JAEL). If so, words will be more difficult to discriminate from extant body rime pseudohomophones than from novel body rime pseudohomophones. The more difficult discrimination should be reflected in slower "yes" response times or higher error rates to words.

\section{Method}

Participants. One hundred twenty undergraduate students enrolled at Arizona State University participated in partial fulfillment of a course requirement. All were native speakers of English with normal or corrected vision and were tested individually. Each was randomly assigned to one of the three between-subjects conditions: extant body rime, novel body rime, or control.

Stimuli. Font, stimulus size, and presentation conditions were identical to those of Experiment 1. Each condition included 4 sample trials ( 2 words and 2 nonhomophonic nonwords), 40 practice trials, and 84 experimental trials. Practice trials presented 20 words and 20 nonhomophonic pseudowords. Experimental trials presented 21 high-frequency words, 21 low-frequency words, 14 pseudohomophones (or 18 controls), and 28 (or 24) filler pseudowords as we explain next.

Pseudohomophones and controls. Two matched sets of 14 pseudohomophones were constructed. One set of pseudohomophones contained extant body rimes (JALE), and the other contained novel body rimes (JAEL). Extant body rime pseudohomophones and novel body rime pseudohomophones were matched closely on the basis of their sound-alike word; 10 of 14 shared the same base word. Yoked controls (JARL) were constructed by changing one letter of a pseudohomophone's base word (the 10 pseudohomophone pairs that shared base words also shared the same control). Altogether, the items 
formed 10 yoked triplets (e.g., extant pseudohomophone JALE, control JARL, novel pseudohomophone JAEL) and 4 yoked quartets (e.g., extant pseudohomophone WULL, control WOAL, novel pseudohomophone WYNE, control WIME). This yielded a total of 14 extant pseudohomophones, 14 novel pseudohomophones, and 18 controls. The 18 control items were all presented in the same condition. The difference in number of control items (18) versus pseudohomophone items (14) was compensated by fewer filler items in the control condition (24) than in the pseudohomophone conditions (28), to maintain the same balance of yes and no trials. Otherwise, all conditions presented the same filler-pronounceable pseudoword items.

Pseudohomophone and yoked control pairs were matched further on mean OS to base words (extant $=.64, S E=.03$, control $=.72$, $S E=.02$; novel $=.63, S E=.03$, control $=.73, S E=.01)$. Mean base word frequency was matched between yoked pairs of pseudohomophones $($ extant $=52$ per million, novel $=53$ per million; Kučera \& Francis, 1967). The mean number of letters was the same (4.41) for all conditions. Pseudohomophones constituted one third of the nonword trials in pseudohomophone conditions (compare Pugh et al., 1994, Experiment 2).

All of the extant body rime pseudohomophones were pronunciation consistent by Experiment 1's criteria, except GRAID (enemies: said and plaid; friends: staid, laid, paid, raid, maid, etc.) Most of Experiment 2's pseudohomophones appeared previously in Experiment 1 , and all 23 of these items were given word pronunciations by all 20 participants. Five novel body rime items were not previously presented (SNAIK, WYNE, BRAIK, BEFE, and LUEP). We verified the five new items in a procedure identical to that of Experiment 1, but with fewer (10) participants. Each new item was given a homophonic pronunciation in the speeded naming task by every participant.

The present verification procedure can be contrasted with a procedure used by Van Orden et al. (1988). Their participants read aloud lists of pseudowords typed on sheets of paper, which included putative pseudohomophones. For an item to pass, 9 of 10 participants had to produce the corresponding word pronunciation. Our present criteria are more conservative, and we used a speeded naming task. Not surprisingly, perhaps, items that passed their test failed our test. Twelve of the 20 pseudohomophones that passed the criteria of Van Orden et al. (1988) failed to pass our criteria (as did 23 of the 40 pseudohomophones from Pugh et al., 1994, Experiment 2).

High- and low-frequency words. High-frequency words had frequencies greater than 100 occurrences per million $(M=144)$ and low-frequency words had frequencies less than 10 occurrences per million $(M=7$; Kučera \& Francis, 1967). Word items were held constant while task demands were changed across the manipulation of nonwords. This is an ideal strategy manipulation. An ideal strategy manipulation allows us to attribute the effect of task demands, on word responding, to the hypothetical basis of control in lexical decision (Gibbs \& Van Orden, 1998; Stone \& Van Orden, 1993).

Procedure. Each student participant read instructions from the screen: "If the presented stimulus was an English word, press the yes key (/) on the lower right of the keyboard. If the stimulus was not an English word, press the no key (F9) on the lower left of the keyboard." Each trial began with a fixation (+), visible for $500 \mathrm{msec}$, at the center of the screen (and the forthcoming letter string). After the $500 \mathrm{msec}$, the fixation was replaced immediately by a letter string that remained visible until the participant responded. Successive trials were separated by an 800 -msec intertrial interval. Every trial presented accuracy feedback. A session began with 4 sample trials, during which students could ask procedural questions. This was followed by 40 practice trials and a second opportunity for questions just prior to the 84 experimental trials. Stimulus order was randomized for each participant.

Nonword type was manipulated between-subjects- 40 students saw pseudohomophones with extant body rimes in 14 of the 84 experimental trials, 40 students saw pseudohomophones with novel body rimes on those 14 trials, and 40 students saw yoked control pseudowords but no pseudohomophones. Word frequency was manipulated within subjects; all students saw the same high- and lowfrequency words.

\section{Results}

The dependent variables were mean correct RT and percent error (item data are presented in the Appendix; ANOVAs were calculated on proportion error). Planned contrasts were conducted using ANOVAs with participants and items as random factors. Participant $F$ values are indicated by $F_{\mathrm{P}}$, and item $F$ values are indicated by $F_{\mathrm{I}}$. Post hoc analyses were used to check for effects of Coltheart $N$, a potential confound in the body rime manipulation.

Nonword error analyses. Pseudohomophones with extant body rimes yielded slightly more errors $(9.7 \%$, $S E=1.3)$ than did controls $(6.3 \%, S E=1.4)$, an effect that was marginally reliable $\left[F_{\mathrm{P}}(1,78)=3.92, M S_{\mathrm{e}}=\right.$ $\left.0.004, p=.07 ; F_{\mathrm{I}}(1,13)=2.66, M S_{\mathrm{e}}=0.008, p<.13\right]$, and they yielded more errors than did pseudohomophones with novel body rimes $\left[3.9 \%, S E=0.7 ; F_{\mathrm{P}}(1,78)=15.79\right.$, $\left.M S_{\mathrm{e}}=0.005 ; F_{\mathrm{I}}(1,13)=4.43, M S_{\mathrm{e}}=0.007, p<.06\right]$. The error rate for responses to pseudohomophones with novel body rimes $(3.9 \%, S E=0.7)$ was not reliably different from that to yoked controls $[6.0 \%, S E=1.4$; $F_{\mathrm{P}}(1,78)=1.94, M S_{\mathrm{e}}=0.005 ; F_{\mathrm{I}}(1,13)=1.02, M S_{\mathrm{e}}=$ $0.004]$, and the apparent lower error rate to novel pseudohomophones was opposite in direction to the effect produced by extant pseudohomophones.

Nonword RT analyses. Extant body rime pseudohomophones yielded slower correct "no" RTs (846 msec, $S E=16)$ than did their yoked controls [749 msec, $S E=$ $12 ; F_{\mathrm{P}}(1,78)=23.36, M S_{\mathrm{e}}=8,592 ; F_{\mathrm{I}}(1,13)=12.16$, $M S_{\mathrm{e}}=5,068$ ], and slower correct "no" RTs than did pseudohomophones with novel body rimes $[727 \mathrm{msec}$, $S E=15 ; F_{\mathrm{P}}(1,78)=30.24, M S_{\mathrm{e}}=9,869 ; F_{\mathrm{I}}(1,13)=$ $\left.31.54, M S_{\mathrm{e}}=2,718\right]$. In contrast, correct "no" RTs to novel pseudohomophones ( $727 \mathrm{msec}, S E=15)$ did not differ statistically from those to yoked controls [748 msec, $S E=12 ; F_{\mathrm{P}}(1,78)=1.23, M S_{\mathrm{e}}=9,371 ; F_{\mathrm{I}}(1,13)=1.58$, $M S_{\mathrm{e}}=4,247$ ], and they appeared to be slightly faster than RTs to yoked controls.

The results so far: Extant body rime pseudohomophones produced the classic pseudohomophoneeffect; novel body rime pseudohomophones did not.

Table 1

Mean Correct Response Times (in Milliseconds) and

Percent Error for Low - and High-Frequency Words in Each Nonword Context Condition of Experiment 2

\begin{tabular}{|c|c|c|c|c|c|c|}
\hline \multirow[b]{3}{*}{ Nonword Context } & \multicolumn{6}{|c|}{ Word Target } \\
\hline & \multicolumn{2}{|c|}{ Low-Frequency } & \multicolumn{2}{|c|}{ High-Frequency } & \multicolumn{2}{|c|}{ Mean } \\
\hline & RT & $\mathrm{PE}$ & RT & PE & RT & $\mathrm{PE}$ \\
\hline \multicolumn{7}{|l|}{ Pseudohomophones } \\
\hline Extant body rimes & 757 & 14.0 & 629 & 1.1 & 693 & 7.6 \\
\hline Novel body rimes & 730 & 13.0 & 609 & 1.1 & 670 & 7.0 \\
\hline Control nonwords & 718 & 15.6 & 600 & 1.3 & 659 & 8.4 \\
\hline Extant - control & 39 & -1.6 & 29 & -0.2 & 34 & -0.8 \\
\hline Novel - control & 12 & -2.6 & 9 & -0.2 & 11 & -1.4 \\
\hline
\end{tabular}


Word error analyses. Fewer errors were made in responses to high-frequency words than to low-frequency words in all conditions - a standard finding. No other difference was reliable (virtually all $F_{\mathrm{s}}<1$ ).

Word RT analyses. Mean correct RTs and percent errors for words are presented in Table 1. The apparent trend toward slower RTs for words in the novel pseudohomophone condition $(670 \mathrm{msec}, S E=13$, vs. $659 \mathrm{msec}, S E=$ 8 ) was marginal by items $\left[F_{\mathrm{I}}(1,40)=3.85, M S_{\mathrm{e}}=382\right.$, $p<.06]$, but it was not reliable by participants $\left[F_{\mathrm{P}}(1,78)<\right.$ $\left.1, M S_{\mathrm{e}}=5,221\right]$. By contrast, word RTs were reliably slower in the context of extant pseudohomophones than in the control condition $\left[F_{\mathrm{P}}(1,78)=5.83, M S_{\mathrm{e}}=4,677\right.$; $\left.F_{\mathrm{I}}(1,40)=30.98, M S_{\mathrm{e}}=516\right]$. The mean word RT was $693 \mathrm{msec}(S E=11)$ in the extant pseudohomophone context $659 \mathrm{msec}(S E=8)$ in the control condition, a difference of $34 \mathrm{msec}$. In addition, overall word RTs in the extant body rime condition $(693 \mathrm{msec})$ were reliably slower (by items, but not by participants) than word RTs in the novel body rime condition $\left[670 \mathrm{msec} ; F_{\mathrm{P}}(1,78)=\right.$ $\left.1.91, M S_{\mathrm{e}}=6,180 ; F_{\mathrm{I}}(1,40)=13.12, M S_{\mathrm{e}}=591\right]$.

The word error data are not very informative, but the word RT data corroborate our hypothesis. A context of extant body rime pseudohomophones slows word RTs in the lexical decision task. Even RTs to high-frequency words are slower in a context of extant body rime pseudohomophones $(M=629 \mathrm{msec}, S E=10)$ in comparison with the control condition $\left[600 \mathrm{msec}, S E=8 ; F_{\mathrm{p}}(1,78)=\right.$ $\left.5.08, M S_{\mathrm{e}}=1,753 ; F_{\mathrm{I}}(1,20)=14.89, M S_{\mathrm{e}}=3,258\right]$. High-frequency words are usually assumed to make no reference to phonology. But extant body rimes are defined by the relation between pronunciations and spelling, clearly qualifying this as a phonology effect (see related discussion in Stone \& Van Orden, 1993).

Post hoc analyses. We tested for an effect of Coltheart $N$ that was partly confounded with the body rime manipulation in our pseudohomophones. Nevertheless, the correlation between $N$ and performance to extant pseudohomophones $(N=4-14)$ yielded a statistically unreliable correlation for RT data $(r=.10)$ and a statistically unreliable correlation in the wrong direction for error data $(r=-.28)$. Likewise, the correlations between $N$ and performances on novel pseudohomophones $(N=$ $0-6)$ were statistically unreliable for both RT $(r=.23)$ and error data $(r=.26)$.

Lumping extant and novel pseudohomophonestogether in the same analysis, however, yields a statistically reliable correlation with correct " $n o$ " RT data $[r=.61, F(1,26)=$ 15.64] - but not error data $(r=.19)$. This makes sense, because $N$ is now better correlated with the body rime manipulation. We may examine more closely the correlation of $N$ and RT using partial $r^{2} . N$ accounted for only $1 \%$ of RT variance, after the contribution of body rime status was excluded. Thus the correlation of $N$ with RT data may be spurious. By contrast, the unique contribution of body rime status accounted for $31 \%$ of RT variance. All these results corroborate that the reliable effects of the body rime manipulation are not due to a confound with $N$.

\section{GENERAL DISCUSSION}

At the beginning of this article, we noted that experimental studies of pseudohomophones have produced mixed results. The status of a pseudohomophone's body rime relation appears to have been one basis for these mixed results. Extant body rime pseudohomophones (JALE) produce slower lexical decision responses than do controls (JARL); novel body rime pseudohomophones (JAEL) do not. Also, correct yes response times to words are reliably slower in a context of extant body rime pseudohomophones, but not in context of novel body rime pseudohomophones. Comparable results are found for proofreading. Vanhoy (1997) substituted the same pseudohomophone and control items for their base words in a text, and participants were instructed to mark misspellings. Reliably more extant pseudohomophone (JALE) misspellings were missed $(9.1 \%)$ than control misspellings (JARL, 3.2\%) or novel pseudohomophone misspellings (JAEL, $2.1 \%$ ). Apparently, identical word phonology and similarity in spelling do not, by themselves, determine similarity between pseudohomophones and words. Similarity takes into account the relation between body and rime that defines extant body rime pseudohomophones.

\section{REFERENCES}

ANDREws, S. (1982). Phonological recoding: Is the regularity effect consistent? Memory \& Cognition, 10, 565-575.

ANDREws, S. (1997). The effect of orthographic similarity on lexical retrieval: Resolving neighborhood conflicts. Psychonomic Bulletin \& Review, 4, 439-461.

Besner, D., \& DavelaAr, E. (1983). Suedohomofoan effects in visual word recognition: Evidence for phonological processing. Canadian Journal of Psychology, 37, 300-305.

Bosman, A. M. T., \& DE Groot, A. M. B. (1996). Phonologic mediation is fundamental to reading: Evidence from beginning readers. Quarterly Journal of Experimental Psychology, 49A, 715-744.

Coltheart, M., Davelaar, E., Jonasson, J. T., \& Besner, D. (1977). Access to the internal lexicon. In S. Dornic (Ed.), Attention and performance VI (pp. 535-555). London: Academic Press.

Coltheart, V., Avons, S. E., Masterson, J., \& Laxon, V. J. (1991) The role of assembled phonology in reading comprehension. Memory \& Cognition, 19, 387-400.

Davelaar, E., Coltheart, M., Besner, D., \& Jonasson, J. T. (1978). Phonological recoding and lexical access. Memory \& Cognition, 6, 391-402.

FARRAR, W. T., \& VAN ORdEn, G. C. (2000). Errors as multistable response options. Nonlinear Dynamics, Psychology, \& Life Sciences, 5, 223-265.

Fera, P., \& Besner, D. (1992). The process of lexical decision: More words about a parallel distributed processing model. Journal of Experimental Psychology: Learning, Memory, \& Cognition, 18, 749-764.

Frost, S. J., Fowler, C. A., \& RueckL, J. G. (1998). Bidirectional consistency: Effects of a phonologycommon to speech and reading. Manuscript submitted for publication.

GibBs, P., \& VAN Orden, G. C. (1998). Pathway selection's utility for control of word recognition. Journal of Experimental Psychology: Human Perception \& Performance, 24, 1162-1187.

GlushKo, R. (1979). The organization and activation of orthographic knowledge in reading aloud. Journal of Experimental Psychology: Human Perception \& Performance, 5, 674-691.

JAMES, C. T. (1975). The role of semantic information in lexical decisions. Journal of Experimental Psychology: Human Perception \& Performance, 1, 130-136.

JARED, D. (1997). Spelling-sound consistency affects the naming of high-frequency words. Journal of Memory \& Language, 36, 505-529. 
Jared, D., McRae, K., \& Seidenberg, M. S. (1990). The basis of consistency effects in word naming. Journal of Memory \& Language, 29, 687-715.

JARed, D., \& Seidenberg, M. S. (1991). Does word identification in reading proceed from spelling to sound to meaning? Journal of Experimental Psychology: General, 120,358-394.

Kawamoto, A. H., \& Zemblidge, J. (1992). Pronunciation of homographs. Journal of Memory \& Language, 31, 349-374.

KuČERA, H., \& Francis, W. (1967). Computationalanalysis of presentday American English. Providence, RI: Brown University Press.

Laxon, V. J., Masterson, J., Pool, M., \& Keating, C. (1992). Nonword naming: Further exploration of the pseudohomophoneeffect in terms of orthographic Coltheart $N$, graphemic changes, spelling-sound consistency, and reader accuracy. Journal of Experimental Psychology: Learning, Memory, \& Cognition, 18, 730-748.

Lewenstein, M., \& NowaK, A. (1989a). Fully connected neural networks with self-control of noise levels. Physical Review Letters, 62 , 225-228.

LeWEnstein, M., \& NowAK, A. (1989b). Recognition with self-control in neural networks. Physical Review A, 40, 4652-4664.

Lukatela, G., \& Turvey, M. T. (1991). Phonological access of the lexicon: Evidence from association priming with pseudohomophones. Journal of Experimental Psychology: Human Perception \& Performance, 17, 951-966.

Lukatela, G., \& Turvey, M. T. (1994). Visual lexical access is initially phonological: Evidence from association priming by words, homophones, and pseudohomophones. Journal of Experimental Psychology: General, 123, 107-128.

Lukatela, G., \& Turvey, M. T. (2000). An evaluation of the twocycles model of phonology assembly. Journal of Memory \& Language, 42, 183-207.

Martin, R. C. (1982). The pseudohomophone effect: The role of visual similarity in non-word decisions. Quarterly Journal of Experimental Psychology, 34A, 395-410.

McCANn, R. S., \& Besner, D. (1987). Reading pseudohomophones: Implications for models of pronunciation assembly and the locus of word-frequency effects in naming. Journal of Experimental Psychology: Human Perception \& Performance, 13, 14-24.

McCann, R. S., Besner, D., \& DavelaAr, E. (1988). Word recognition and identification: Do word-frequency effects reflect lexical access? Journal of Experimental Psychology: Human Perception \& Performance, 14, 693-706.

McQuAdE, D. V. (1981). Variable reliance on phonological information in visual word recognition. Language \& Speech, 24, 99-109.

McRae, K., JARed, D., \& SeidenberG, M. S. (1990). On the roles of frequency and lexical access in word naming. Journal of Memory \& Language, 29, 43-65.

Meyer, D. E., \& RudDy, M. G. (1973, November). Lexical-memory retrieval based on graphemic and phonemic representations of printed words. Paper presented at the meeting of the Psychonomic Society, St. Louis.

Patterson, K., \& Behrmann, M. (1997). Frequency and consistency effects in a pure surface dyslexic patient. Journal of Experimental Psychology: Human Perception \& Performance, 23, 1217-1231.

Perea, M. (1998). Orthographic neighbours are not all equal: Evidence using an identification technique. Language \& Cognitive Processes, 13, 77-90.

Pexman, P. M., Lupker, S. J., Jared, D., Toplak, M., \& Rouibah, A. (1996, November). Strategically controlling phonology in response to pseudohomophones? Paper presented at the 37th Annual Meeting of the Psychonomic Society, Chicago.

Plaut, D. C. (1997) Structure and function in the lexical system: Insights from distributed models of word reading and lexical decision. Language \& Cognitive Processes, 12, 765-805.

Pugh, K. R., Rexer, K., \& Katz, L. (1994). Evidence of flexible coding in visual word recognition. Journal of Experimental Psychology: Human Perception \& Performance, 20, 807-825.

Rubenstein, H., Lewis, S. S., \& Rubenstein, M. A. (1971). Evidence for phonemic recoding in visual word recognition. Journal of Verbal Learning \& Verbal Behavior, 10, 645-657.
Seidenberg, M. S., Plaut, D. C., Petersen, A. S., McClelland, J. L., \& McRAE, K. (1994). Nonword pronunciation and models of word recognition. Journal of Experimental Psychology: Human Perception \& Performance, 20, 1177-1196.

Skarda, C. A., \& Freeman, W. J. (1987). How brains make chaos in order to make sense of the world. Behavioral \& Brain Sciences, 10, 161-195.

SPieler, D. H., \& BAlota, D. A. (1997). Bringing computational models of word naming down to the item level. Psychological Science, $\mathbf{8}$, 411-416.

Stone, G. O., Vanhoy, M., \& Van Orden, G. C. (1997). Perception is a two-way street: Feedforward and feedback phonologyin visual word recognition. Journal of Memory \& Language, 36, 337-359.

Stone, G. O., \& VAN Orden, G. C. (1992). Resolving empirical inconsistencies concerning priming, frequency, and nonword foils in lexical decision. Language \& Speech, 35, 295-324.

Stone, G. O., \& Van Orden, G. C. (1993). Strategic control of processing in word recognition. Journal of Experimental Psychology: Human Perception \& Performance, 19, 744-774.

Stone, G. O., \& Van Orden, G. C. (1994). Building a resonance framework using design and system principles. Journal of Experimental Psychology: Human Perception \& Performance, 20, 1248-1268.

TAFT, M., \& VAN GRAAN, F. (1998). Lack of phonological mediation in a semantic categorization task. Journal of Memory \& Language, $\mathbf{3 8}$, 203-224.

VAllacher, R. R., \& NowAK, A. (1997). The emergence of dynamical social psychology. Psychological Inquiry, 8, 73-99.

VANHOY, M. (1997). What are pseudohomophones? Unpublished doctoral dissertation. Arizona State University.

VAn ORden, G. C. (1987). A ROWS is a ROSE: Spelling, sound, and reading. Memory \& Cognition, 15, 181-198.

VAN Orden, G. C., \& Goldinger, S. D. (1994). Interdependence of form and function in cognitive systems explains perception of printed words. Journal of Experimental Psychology: Human Perception \& Performance, 20, 1269-1291.

Van Orden, G. C., Johnston, J. C., \& Hale, B. L. (1988). Word identification in reading proceeds from spelling to sound to meaning. Journal of Experimental Psychology: Learning, Memory, \& Cognition, 14, 371-386.

Van Orden, G. C., Pennington, B. F., \& Stone, G. O. (1990). Word identification and the promise of subsymbolic psycholinguistics. Psychological Review, 97, 488-522.

Van Orden, G. C., Stone, G. O., Garlington, K. L., Markson, L. R. Pinnt, G. S., Simonfy, C. M., \& Brichetto, T. (1992). "Assembled" phonology and reading: A case study in how theoretical perspective shapes empirical investigation. In R. Frost \& L. Katz (Eds.), Orthography, phonology, morphology, and meaning (pp. 249-292). Amsterdam: Elsevier.

Ziegler, J. C., Montant, M., \& Jacobs, A. M. (1997). The feedback consistency effect in lexical decision and naming. Journal of Memory \& Language, 37, 533-554.

Ziegler, J. C., \& Perry, C. (1998). No more problems in Coltheart's neighborhood: Resolving neighborhood conflicts in the lexical decision task. Cognition, 68, B53-B62.

Ziegler, J. C., \& VAN Orden, G. C. (2000). Feedback consistency effects and subjective familiarity. Manuscript submitted for publication.

\section{NOTES}

1. Other reports of faster correct word responses in pseudohomophone conditions include Andrews (1982) and Davelaar, M. Coltheart, Besner, and Jonasson (1978). Andrews's (1982) finding is disqualified by a speed-accuracy tradeoff; see Stone and Van Orden (1993) for discussion. Davelaar et al.'s finding is disqualified by the use of different words across conditions. If the same words appear in all nonword context contrasts, the pattern is slower RTs to words in the pseudohomophone condition (Pexman, Lupker, Jared, Toplak, \& Rouibah, 1996).

2. It is possible that Pugh et al.'s (1994) key results are not replicable. Gibbs and Van Orden (1998) discuss this point; Pexman et al. (1996) report several failures to replicate. 
APPENDIX

Mean RT (in Milliseconds) and Percent Error to

Pseudohomophone and Control Items of Experiment 2

\begin{tabular}{lrrlrrlllllr}
\hline $\begin{array}{c}\text { Extant } \\
\text { Body Rimes }\end{array}$ & RT & \multicolumn{1}{c}{ PE } & Controls & RT & \multicolumn{1}{c}{ PE } & Body Rimes & RT & PE & Controls & RT & PE \\
\hline BEAF & 860 & 29.5 & BELF & 725 & 2.5 & BEFE & 706 & 0.0 & & \\
BERD & 796 & 0.0 & BRID & 882 & 12.5 & BAHM & 705 & 4.8 & BEMB & 678 & 5.0 \\
BERN & 807 & 9.1 & BRUN & 741 & 2.5 & BRAIK & 719 & 2.4 & BREEK & 831 & 12.5 \\
BOCKS & 953 & 9.1 & BIX & 699 & 5.0 & BAWX & 712 & 0.0 & & \\
COAP & 785 & 18.2 & CIPE & 707 & 2.5 & COEP & 760 & 7.1 & & \\
GRAID & 814 & 13.6 & GRIDE & 823 & 27.5 & GRAYD & 698 & 2.4 & & \\
JALE & 899 & 4.5 & JARL & 699 & 0.0 & JAEL & 696 & 2.4 & & \\
LOUP & 819 & 13.6 & LOIP & 662 & 2.5 & LUEP & 651 & 0.0 & & \\
LURN & 779 & 9.1 & LOARN & 836 & 0.0 & LIRN & 753 & 4.8 & & \\
NERSE & 874 & 2.3 & NARSE & 723 & 0.0 & NIRSE & 844 & 11.9 & & \\
SCUNK & 896 & 27.9 & SKONK & 690 & 0.0 & SNAIK & 753 & 2.4 & SNAPE & 933 \\
SOPE & 825 & 2.3 & SIAP & 689 & 0.0 & SEWP & 711 & 7.1 & & \\
TEECH & 856 & 6.8 & TOACH & 813 & 10.0 & TIECH & 694 & 0.0 & & \\
WULL & 771 & 0.0 & WOAL & 729 & 5.0 & WYNE & 779 & 9.5 & WIME & 798 & 7.5 \\
\hline
\end{tabular}

(Manuscript received July 6, 1999;

revision accepted for publication September 8, 2000.) 